\title{
Inositol hexaphosphate limits the migration and the invasiveness of colorectal carcinoma cells in vitro
}

\author{
LADISLAVA SCHRÖTEROVÁ ${ }^{1}$, ALENA JEŽKOVÁ ${ }^{2}$, EMIL RUDOLF $^{1}$, KATEŘINA CALTOVÁ ${ }^{1}$, \\ VĚRA KRÁLOVÁ ${ }^{1}$ and VERONIKA HANUŠOVÁ ${ }^{1}$ \\ ${ }^{1}$ Department of Medical Biology and Genetics, Charles University, Faculty of Medicine in Hradec Králové, \\ 50003 Hradec Králové; ${ }^{2}$ Department of Biochemical Sciences, Charles University, \\ Faculty of Pharmacy, 50005 Hradec Králové, Czech Republic
}

Received October 24, 2017; Accepted June 1, 2018

DOI: $10.3892 / \mathrm{ijo} .2018 .4488$

\begin{abstract}
Inositol hexaphosphate (IP6), also known as phytic acid, has been shown to exhibit anticancer effects in a number of preclinical tumor models. IP6 decreases proliferation by arresting cells in the G0/G1 phase, inhibits iron-mediated oxidative reactions, enhances differentiation and stimulates apoptosis. The present study attempted to characterize the effect of IP6 on the migration and adhesion of colon cancer SW620 cells. IP6 was assessed at concentrations of 0.2 and $1 \mathrm{mM}$ during 12, 24 and $48 \mathrm{~h}$ of exposure. Migration ability was measured with the real-time xCELLigence Real-Time Cell Analyzer Dual Purpose system. The expression of mRNA and proteins involved in migration and cancer progression [epithelial cell adhesion molecule, intercellular adhesion molecule-1, $\beta$-catenin, $\mathrm{N}$-cadherin, E-cadherin, matrix metalloproteinase (MMP)-2 and MMP-9] was determined by reverse transcription-quantitative polymerase chain reaction and western blot analysis. The changes in the expression and subcellular localization of E-cadherin were determined by indirect immunofluorescence. IP6 induced a decrease in the migration ability of the tested SW620 cell line. IP6-treated cells also showed decreased expression of $\mathrm{N}$-cadherin, increased levels of E-cadherin and decreased expression of MMP-2 and MMP-9. These results indicated that IP6 has potential
\end{abstract}

Correspondence to: Dr Ladislava Schröterová, Department of Medical Biology and Genetics, Charles University, Faculty of Medicine in Hradec Králové, 870 Šimkova, 50003 Hradec Králové, Czech Republic

E-mail: schroteroval@lfhk.cuni.cz

Abbreviations: CRC, colorectal cancer; DMEM, Dulbecco's modified Eagle's medium; EpCAM, epithelial cell adhesion molecule; FBS, fetal bovine serum; ICAM-1, intercellular adhesion molecule 1; IP6, inositol hexaphosphate; MMP, matrix metalloproteinase; PBS, phosphate-buffered saline; RT-qPCR, reverse transcriptionquantitative polymerase chain reaction; TBST, Tris-buffered saline (TBS) plus Tween-20

Key words: phytic acid, inositol hexaphosphate, colorectal cancer, SW620, migration, proliferation, invasion to modulate the migration ability and expression of markers associated with invasion in SW620 cells; however, further analysis is necessary to obtain a detailed understanding of the mechanism of action.

\section{Introduction}

Cancer represents one of the leading causes of morbidity and mortality globally, with $\sim 14$ million new cases and 8.2 million cancer-associated mortalities in 2012. It has been predicted that the number of cancer cases will increase from the recorded 14 million in 2012 to 22 million per year within the next 2 decades (1). Colorectal cancer (CRC) is the third most frequent cancer diagnosis in men and the second most frequent in women worldwide; however, the incidence of CRC varies significantly among different countries (2). While surgical resection is a successful treatment modality in the early stages of this malignancy, the treatment options for the advanced stages of colorectal cancer remain limited in terms of their efficiency due to the generalized spread of tumor cells and their acquired chemoresistance.

Novel strategies to improve cancer treatment have been intensively investigated, including the search for substances with anticancer effects. Among the natural extracts with possible anticancer activity, inositol hexaphosphate (IP6), also known as phytic acid, represents a promising option. IP6 has been studied in vivo and in vitro in different types of cancer tissues and cells, including those of the colon (3), breast (4), liver (5), prostate (6), skin (7) and bladder (8). In these studies, IP6 was reported to arrest cellular proliferation in the G0/G1 phase (9), inhibit iron-mediated oxidative reactions (10), enhance differentiation and stimulate apoptosis (10), and regulate the process of cellular differentiation (11-13). Furthermore, published studies have suggested that IP6 may also affect the invasion and migration of cancer cells in vitro and in vivo. In one previous study, IP6 prevented the colorectal cancer development and metastatic progression to the liver in BALB/c mice by altering the expression of several extracellular matrix proteins, the proteolytic enzyme matrix metalloproteinase (MMP)-9, and other angiogenic and growth factors (14). The expression of the matrix metalloproteinases and tissue inhibitors of MMPs (TIMPs) was also studied in 
an unstimulated and IL-1 $\beta$-stimulated colon cancer Caco-2 cell line exposed to IP6. The results showed that IP6 exerts its inhibitory activity through modulation of MMP and TIMP gene expression to prevent the migration and invasion of cancer cells (15). In the breast cancer MDA-MB231 cell line, treatment with IP6 resulted in a $65 \%$ reduction of cell adhesion to fibronectin and a $37 \%$ reduction to collagen, while also decreasing the number of migrating cells. Additionally, IP6 significantly inhibited MMP-9 secretion (16) and modulated integrin dimerization, cell surface expression and the integrin-associated signaling pathway (17). The present study was designed to evaluate the effect of IP6 on cell migration and on the expression of adhesion and invasion markers in the colorectal cancer SW620 cell line.

\section{Materials and methods}

Cell culture and treatment. The continuous SW620 cell line (catalog no. CCL-227; American Type Culture Collection, Manassas, VA, USA) was routinely maintained in a humidified $5 \% \mathrm{CO}_{2}$ atmosphere at $37^{\circ} \mathrm{C}$ in Dulbecco's modified Eagle's medium (DMEM) (catalog no. D5796; Sigma-Aldrich; Merck KGaA, Darmstadt, Germany) with $10 \%$ fetal bovine serum (Gibco; Thermo Fisher Scientific, Inc., Waltham, MA, USA) and penicillin/streptomycin (100 U/ml; Gibco; Thermo Fisher Scientific, Inc.). Stock solutions of IP6 (catalog no. P5681; Sigma-Aldrich; Merck KGaA) were prepared in PBS without calcium and magnesium ions and stored in a refrigerator until use. Since IP6 shows poor solubility in the standard DMEM with $10 \%$ fetal bovine serum, Nutrient Mixture F-12 Ham (catalog no. N-4888) with 1\% FBS and $1 \%$ L-glutamine (catalog no. G7513) (both from Sigma-Aldrich; Merck KGaA) was used in all experiments. Experiments were repeated at least three times. Cultures were regularly checked for the presence of mycoplasmas.

Cell migration assay. A cell migration assay was performed using the xCELLigence Real-Time Cell Analyzer Dual Purpose (RTCA-DP) system (Roche Diagnostics, Basel, Switzerland). The upper chamber of CIM-plate 16 were filled with $1 \%$ bovine serum albumin-supplemented Ham's F-12 medium and the lower chamber was filled with Ham's F-12 medium supplemented with $10 \%$ FBS. The plate was placed in an incubator for $1 \mathrm{~h}\left(37^{\circ} \mathrm{C}, 5 \% \mathrm{CO}_{2}\right)$ for equilibration of a background. Defined amounts of cells $(30,000$ cells $/ 100 \mu \mathrm{l})$ with the test substance $(0.2$ or $1 \mathrm{mM}$ IP6) were added into the upper chamber, the plates were inserted into the instrument and the cells were allowed to migrate to the lower chambers for $24 \mathrm{~h}$. The impedance (corresponding to cell migration) was measured every $10 \mathrm{~min}$.

Reverse transcription-quantitative polymerase chain reaction (RT-qPCR). Cells were cultivated in the 6-well plates at a density of 150000 cells $/ \mathrm{ml}$ (in $2 \mathrm{ml}$ total volume) for $24 \mathrm{~h}$ $\left(37^{\circ} \mathrm{C}, 5 \% \mathrm{CO}_{2}\right)$. Next, the cells were treated for 12,24 and $48 \mathrm{~h}$ with 0.2 and $1 \mathrm{mM}$ concentrations of IP6. RNA was isolated using TriReagent (Sigma-Aldrich; Merck KGaA) according to the manufacturer's recommendations. The purity of the extracted RNA was measured using a NanoDrop ND-2000 UV-VIS spectrophotometer (Thermo Fisher Scientific, Inc.).
cDNA was synthetized from $0.5 \mu \mathrm{g}$ extracted RNA using random hexamers primer, dNTP mix, RiboLock RNase inhibitor and M-MULV reverse transcriptase according to the kit protocol (RevertAid First Strand cDNA Synthesis kit; catalog no. K1622; Thermo Fisher Scientific, Inc.). cDNA synthesis started with initial denaturation of $0.5 \mu \mathrm{g}$ RNA and random hexamers primer $\left(70^{\circ} \mathrm{C}\right.$ for $\left.5 \mathrm{~min}\right)$ and continued with other reagents (whole volume $20 \mu \mathrm{l}$ ) for $5 \mathrm{~min}$ at $25^{\circ} \mathrm{C}$, for $60 \mathrm{~min}$ at $37^{\circ} \mathrm{C}$ and then for $5 \mathrm{~min}$ at $70^{\circ} \mathrm{C}$. Obtained cDNA was stored at $-20^{\circ} \mathrm{C}$ until the qPCR assay.

RT-qPCR of target genes [ $\beta$-catenin, E-cadherin, $\mathrm{N}$-cadherin, epithelial cell adhesion molecule (EpCam), intercellular adhesion molecule-1 (ICAM-1), MMP-2, MMP-9] and a reference housekeeping gene (GAPDH) was performed in a LightCycler 1.5 Real-Time PCR Detection system (Roche Diagnostics). cDNA was diluted five times. The assay was performed using Master mix (whole volume $40 \mu \mathrm{l}$; Roche Diagnostics) containing SYBR-Green $(25 \mu \mathrm{l})$, forward primer $(1 \mu 1,10 \mathrm{mM})$, reverse primer $(1 \mu 1,10 \mathrm{mM})$ and diethyl pyrocarbonate water $(13 \mu \mathrm{l})$. The PCR was initialized with a denaturation step of $10 \mathrm{~min}$ at $95^{\circ} \mathrm{C}$, followed by 40 cycles of amplification as follows: Denaturation for $10 \mathrm{sec}$ at $95^{\circ} \mathrm{C}$, annealing for $15 \mathrm{sec}$ at $60^{\circ} \mathrm{C}$ and extension for $20 \mathrm{sec}$ at $72^{\circ} \mathrm{C}$. A dissociation protocol with a gradient $\left(0.5^{\circ} \mathrm{C}\right.$ every $\left.2 \mathrm{sec}\right)$ from 65 to $95^{\circ} \mathrm{C}$ was used to investigate the specificity of the RT-qPCR and the presence of primer dimers. The amounts of mRNA of target genes were normalized to the GAPDH reference gene. Calculations were based on the $2^{-\Delta \Delta C \mathrm{Cq}}$ method (18). The data are expressed as the fold increase of the untreated cells (=1). Statistical analysis was performed using a one-way analysis of variance (ANOVA) with Bonferroni's modification.

Western blot analysis. Cells were cultivated in 6-well plates at a density of 150,000 cells $/ \mathrm{ml}$ (in $2 \mathrm{ml}$ total volume) for $24 \mathrm{~h}\left(37^{\circ} \mathrm{C}, 5 \% \mathrm{CO}_{2}\right)$. Next, the cells were treated with 0.2 or $1 \mathrm{mM}$ concentrations of IP6 for 12,24 and $48 \mathrm{~h}$. The cells were washed with PBS and harvested in ice-cold lysis buffer $(50 \mathrm{mM}$ Tris- $\mathrm{HCl}, 150 \mathrm{mM} \mathrm{NaCl}, 10 \%$ glycerol, $1 \%$ Triton X-100, 2 mM EDTA, 2 mM EGTA, $\beta$-glycerophosphate, $50 \mathrm{mM} \mathrm{NaF}$, $10 \mathrm{mM}$ sodium pyrophosphate, $200 \mu \mathrm{M}$ sodiumorthovanadate and $2 \mathrm{mM}$ DTT), and the amount of protein in the lysates was measured by bicinchoninic acid assay. Protein lysates were diluted with SDS to a final concentration of $1 \mu \mathrm{g} / \mu \mathrm{l}$. Lysates (30 $\mu \mathrm{l})$ were loaded onto the $10 \%$ SDS-polyacrylamide gel $(0.1 \%$ SDS $)$ and transferred to a polyvinylidene difluoride membrane $(100 \mathrm{~V}, 90 \mathrm{~min})$, and then blocked at $25^{\circ} \mathrm{C}$ for $1.5 \mathrm{~h}$ with a solution containing $5 \%$ skimmed dry milk, $10 \mathrm{mM}$ Tris- $\mathrm{HCl}$ (pH 8.0), $150 \mathrm{mM}$ sodium chloride and $0.1 \%$ Tween-20 (TBST). Membranes were then incubated at $4^{\circ} \mathrm{C}$ overnight with the following primary antibodies: Polyclonal rabbit anti-cluster of differentiation 54/ICAM-1 (catalog no. $4915 ; 1: 5,000$ dilution) polyclonal rabbit anti- $\beta$-catenin (catalog no. 8480; 1:5,000 dilution), polyclonal rabbit anti-E-cadherin (catalog no. 1395; 1:1,500 dilution), monoclonal mouse anti-EpCAM (catalog no. 2929; 1:2,500 dilution) (all Cell Signaling Technology, Inc., Danvers, MA, USA) and monoclonal mouse anti- $\beta$-actin (catalog no. A5441; 1:10,000 dilution; Sigma-Aldrich; Merck KGaA). This was followed by washing in TBST (6 times for 5 min each). The membranes were then incubated with peroxidase-conjugated secondary 


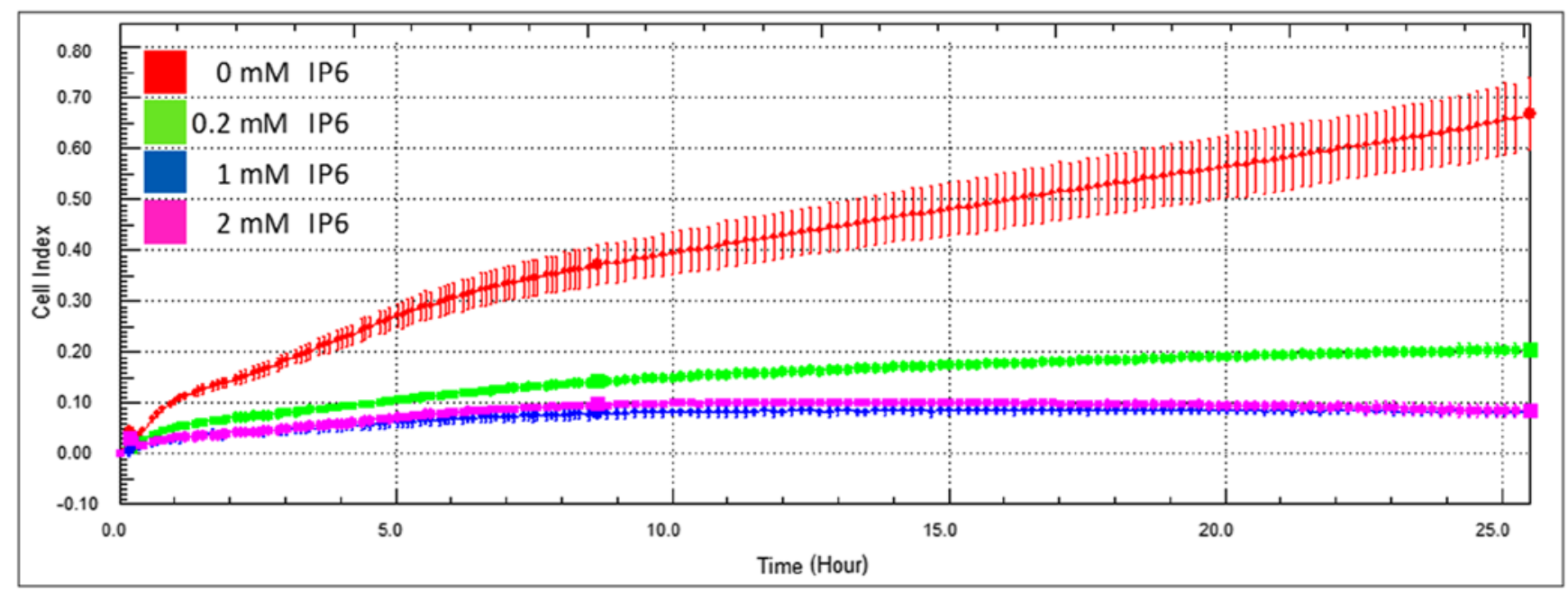

Figure 1. Cell migration assay. Effect of IP6 at concentrations of 0 (control), $0.2,1$ and $2 \mathrm{mM}$ on the migration ability of SW620 cells during $24 \mathrm{~h}$ was measured by X-CELLigence Real-Time Migration Analysis. Migration ability is expressed as cell index. The data represent the mean \pm standard deviation from four biological replicates, selected as representative examples from three independent experiments. IP6, inositol hexaphosphate.

antibodies [1:20,000 dilution; polyclonal swine anti-rabbit immunoglobulin/horseradish peroxidase (HRP)-conjugated; catalog no. P039901-2; polyclonal goat anti-mouse immunoglobulin/HRP-conjugated; catalog no. P044701-2; Agilent Technologies, Inc., Santa Clara, CA, USA] for $2 \mathrm{~h}$ at $25^{\circ} \mathrm{C}$, followed by washing with TBST. Finally, the signal was developed with an Enhanced Chemiluminescence Prime Western Blotting Detection Reagent (Amersham; GE Healthcare Life Sciences, Shanghai, China). The quantity of chemiluminescence was detected using Imaging System Gel Logic 2200 PRO (Molecular Imaging, Inc., Ann Arbor, MI, USA).

Immunofluorescence microscopy. Changes in the expression of E-cadherin in the cells were detected by indirect immunofluorescence. IP6 was tested at concentrations of 0.2 and $1 \mathrm{mM}$ at three time intervals (24, 48 and $72 \mathrm{~h}$ ). Treated and control cells grown in cytospin chambers were rinsed with PBS and fixed in $2 \%$ paraformaldehyde (20 min at room temperature). Following rinsing in PBS, samples were incubated with skimmed milk (5\% solution in PBS; $30 \mathrm{~min}$, room temperature) and primary mouse anti-E-cadherin antibody (catalog no. 14472; 1:100 dilution; Cell Signaling Technology, Inc.) was added for $2 \mathrm{~h}$ at $4^{\circ} \mathrm{C}$ in the dark. Cells were then rinsed three times in PBS and Alexa Fluor 488-labeled goat anti-mouse immunoglobulin G secondary antibody (catalog no. 150113; 1:250 dilution; Abcam, Cambridge, UK) was added for $1 \mathrm{~h}$ at room temperature. At the end of incubation, cells were postlabeled with 4',6-diamidino-2-phenylindole for $10 \mathrm{~min}$ at $4^{\circ} \mathrm{C}$, and then washed in PBS and mounted into Prolong Gold antifade medium (catalog no. 8961; Cell Signaling Technology, Inc.). Slides were examined using an epifluorescence microscope (Nikon Eclipse E400; Nikon Corporation, Tokyo, Japan) and the expression of E-cadherin was evaluated using image analysis software (LUCIA DI Image Analysis System LIM; Laboratory Imaging Ltd., Prague, Czech Republic) in at least 2,000 cells per sample.

Statistical analysis. Statistical analysis was performed using one-way ANOVA with Bonferroni's modification using
GraphPad Prism 7 (GraphPad Software, Inc., La Jolla, CA, USA). Results were compared with control samples (0 mM IP6) and presented as the mean \pm standard deviation. $\mathrm{P}<0.05$ was used to indicate a statistically significant difference. All experiments were completed in at least two independent replicates $(n \geq 2)$.

\section{Results}

Effect of IP6 on migration of SW620 cells. Firstly, the effect of various IP6 concentrations on the migration of colorectal cancer SW620 cells was evaluated. The three tested non-toxic IP6 concentrations $(0.2,1$ and $2 \mathrm{mM})$ were chosen based on our previous experiments (19) and cytotoxicity testing (half maximal inhibitory concentration, $3.63 \mathrm{mM}$ IP6). All tested concentrations significantly decreased the cell migration of the SW620 cells in a dose-dependent manner (Fig. 1). A significantly pronounced effect was already observable using 0.2 and $1 \mathrm{mM}$ concentrations (the effect of a $2 \mathrm{mM}$ concentration of IP6 was comparable with that of a $1 \mathrm{mM}$ concentration of IP6); therefore these two concentrations were chosen for further experiments.

Expression of MMP markers. A significant suppression of the MMPs involved in cancer progression (MMP-2 and MMP-9) at the mRNA levels was observed at the 24 and $48 \mathrm{~h}$ tested time intervals following treatment with 0.2 and $1 \mathrm{mM}$ concentrations of IP6 (Fig. 2).

Expression of adhesion and migration markers. In the next step, the study focused on the expression of selected adhesion and migration markers at the mRNA (Fig. 2) and/or protein levels (Fig. 3). IP6 treatment led to significant decrease in the $\mathrm{N}$-cadherin levels. Changes in the mRNA levels of EpCAM and ICAM could be observed only in isolated time intervals and concentrations (in EpCAM following treatment with $1 \mathrm{mM}$ IP6 at $48 \mathrm{~h}$ and in ICAM-1 following treatment with $1 \mathrm{mM}$ IP6 at 12 and $24 \mathrm{~h}$ ), while the mRNA levels of E-cadherin and $\beta$-catenin were not significantly altered by IP6 at all (Fig. 2). In addition, the protein levels of $\beta$-catenin remained unchanged in 

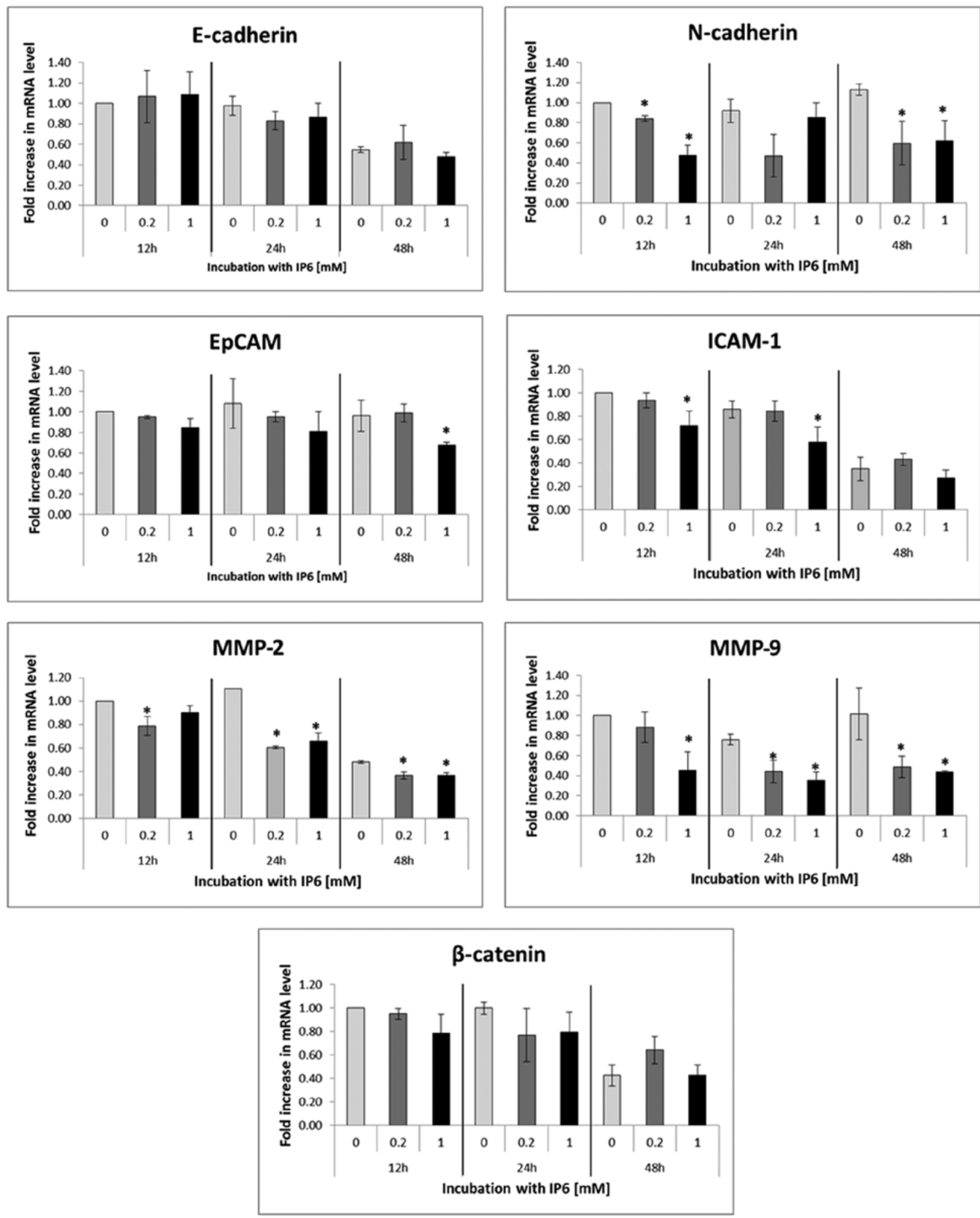

Figure 2. Reverse transcription-quantitative polymerase chain reaction. The changes in relative mRNA expression of molecules involved in cancer progression (MMP2, MMP9, EpCAM, ICAM, E-cadherin, N-cadherin and $\beta$-catenin) following treatment with $0,0.2$ and 1 mM concentrations of IP6 for 12,24 and $48 \mathrm{~h}$. The amounts of mRNA of the target genes was normalized to the GAPDH reference gene. The data are expressed as the fold increase of the untreated cells $(=1)$. "Significant change of means from three independent experiments performed in duplicates $(\mathrm{P}<0.05)$ identified by one-way analysis of variance with Bonferroni's modification. IP6, inositol hexaphosphate; MMP, matrix metalloproteinase; EpCAM, epithelial cell adhesion molecule; ICAM-1, intercellular adhesion molecule 1 .

IP6-treated SW620 cells in all time intervals and concentrations compared with the untreated ( 0 mM IP6) controls $(\mathrm{P}>0.05)$. A significant decrease in EpCAM mRNA expression was observed only at the highest concentration and time interval tested, while ICAM-1 expression decreased transiently at 12 and $24 \mathrm{~h}$ post-treatment with $1 \mathrm{mM}$ IP6. A significant decrease in protein levels in comparison to the control group (0 mM IP6) was observed in EpCAM at the 48-h time interval and at the 

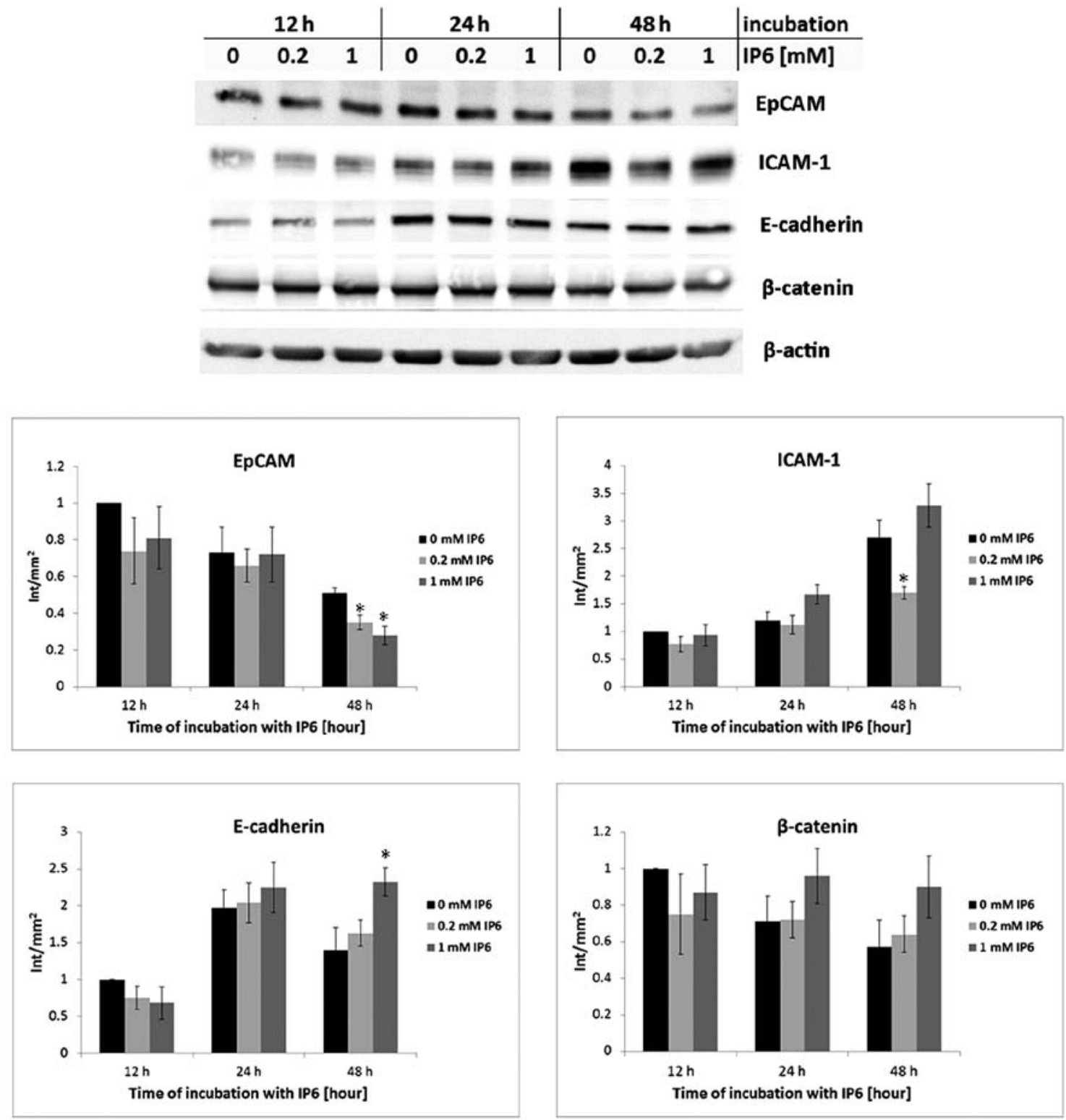

Figure 3. Western blot analysis. Protein expression of ICAM-1, $\beta$-catenin, E-cadherin and EpCAM as determined by immunoblotting analysis in SW620 cells following treatment with $0,0.2$ and $1 \mathrm{mM}$ IP6 for 12,24 or $48 \mathrm{~h}$. The proteins were normalized to the $\beta$-actin housekeeping control, and quantitative analysis of the bands was determined densitometrically as chemiluminiscence $\left(\mathrm{Int} / \mathrm{mm}^{2}\right)$ on the y-axis. The graphs under the bands refer to relative expression of individual proteins in treated cells compared with untreated cells $(=1)$. "Significant change of means from two independent experiments $(\mathrm{P}<0.05)$ identified by one-way analysis of variance with Bonferroni's modification. EpCAM, epithelial cell adhesion molecule; ICAM-1, intercellular adhesion molecule-1; IP6, inositol hexaphosphate.

two tested concentrations, while in ICAM-1, only at the concentration of $0.2 \mathrm{mM} \mathrm{IP6}$ after $48 \mathrm{~h}$. By contrast, a statistically significant increase in E-cadherin at the protein level was found after $48 \mathrm{~h}$ of treatment (1 mM concentration of IP6).

The study also investigated the subcellular localization of E-cadherin following IP6 treatment. Immunofluorescence analysis of E-cadherin expression in IP6-treated SW620 cells demonstrated significantly increased membrane and cortical localization of this molecule (Fig. 4), in particular after 48 and $72 \mathrm{~h}$ of treatment.

\section{Discussion}

It has been suggested that IP6 has a number of biological functions, including a role in signal transduction, cell proliferation and differentiation (20). The anticancer effect of IP6 has been demonstrated in cells isolated from colorectal cancer (3), liver (14), Barrett's oesophagus (21), prostate (22), breast (16), pancreatic (23), skin (7) and rhabdomyosarcoma (24) tissues, where IP6 acted chiefly via suppressed proliferation with concomitantly induced apoptosis.

IP6 has also been shown to exert inhibitory effects on invasiveness and metastasis. A study on the mouse metastatic FSA-1 cell line showed that injecting IP6 intraperitoneally reduced subcutaneously transplanted fibrosarcoma growth in mice and reduced the number of pulmonary metastases (25). Another study confirmed the anti-metastatic effect of IP6 on the invasive breast MDA-MB231 cell line via reduced migration and the inhibition of the secretion of MMP-9 (16). The follow-up study indicated that the inhibition of cancer 


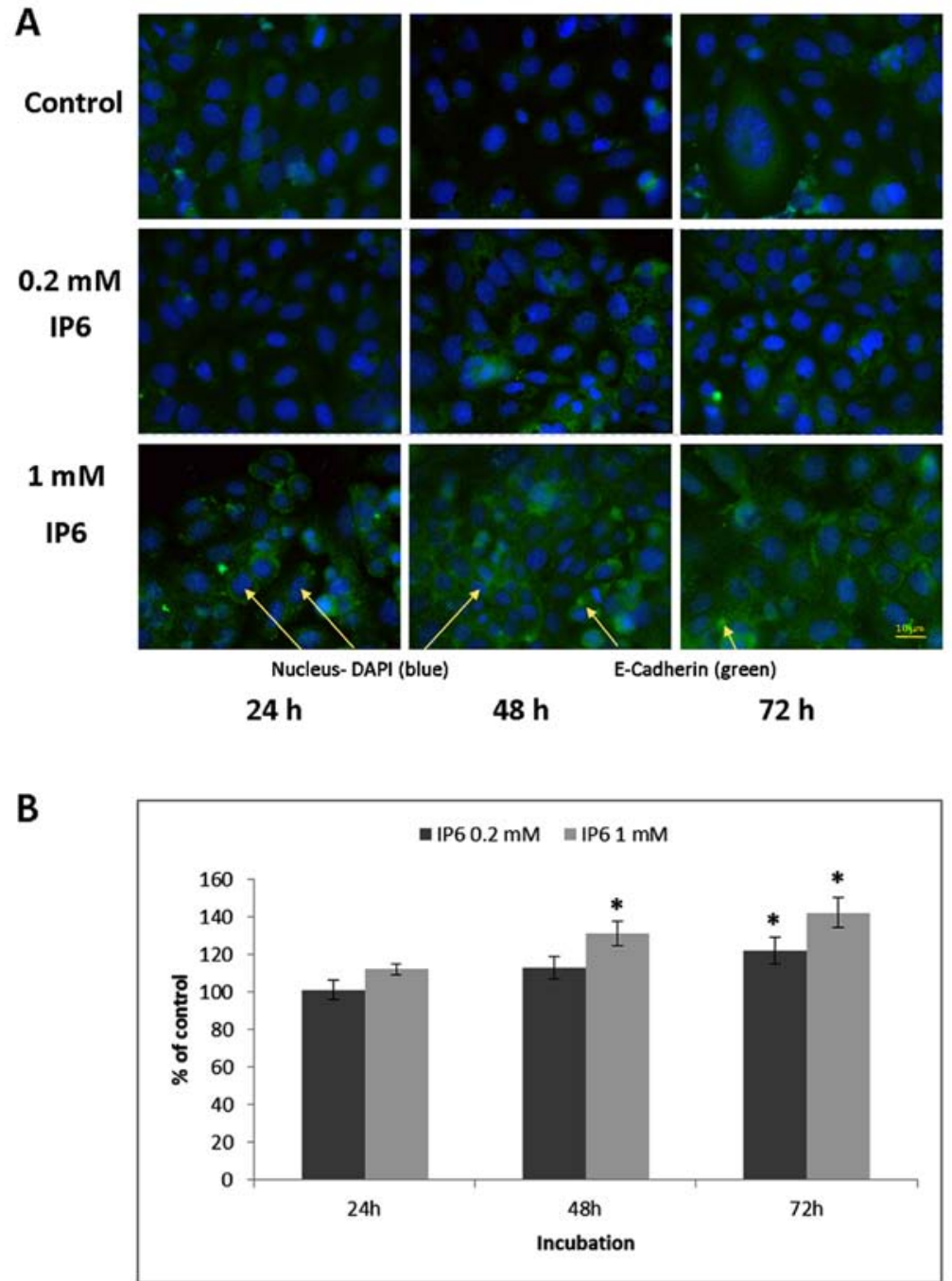

Figure 4. Immunofluorescence microscopy. Effect of IP6 at concentrations of 0 (control), 0.2 and 1 mM on E-cadherin expression and localization after 24 , 48 and $72 \mathrm{~h}$, as determined by means of immunofluorescence microscopy results. (A) Immunofluorescence detection of E-cadherin in the SW620 cells (green fluorescence) in control samples and following treatment with IP6 for 24, 48 and $72 \mathrm{~h}$. The nuclei were counterstained with 4',6-diamidino-2-phenylindole (blue fluorescence) (magnification, x600). (B) Quantification of E-cadherin-exposed cells. Results represent the mean \pm standard deviation of five experiments ${ }^{*} \mathrm{P}<0.05$ compared with the control, using one-way analysis of variance with Bonferroni's modification. IP6, inositol hexaphosphate.

cell adhesion, migration and invasion induced by IP6 may be mediated by modulating integrin dimerization, cell surface expression and the integrin-associated signaling pathway (17).

In the present study, it was found that the concentrations of 0.2 and $1 \mathrm{mM}$ IP6 significantly inhibited the migration of SW620 cells during $24 \mathrm{~h}$ of treatment, as measured using the xCELLigence RTCA-DP system. Furthermore, functioning in a time and concentration manner, IP6 affected the expression of several key molecules involved in cellular adhesion and epithelial to mesenchymal transition. E-cadherin is a transmembrane protein mediating cell adhesion via the E-cadherin- $\beta$-catenin- $\alpha$-catenin complex. A defect in or loss of E-cadherin expression enables the uncontrolled transcriptional activity of $\beta$-catenin in the affected cells, which is associated with the development of invasive and metastatic potential $(26,27)$. To this end, a recently published study on rats with colorectal cancer showed the inhibitory effect of IP6 on $\beta$-catenin activity (28). However, in the present study using the SW620 cell line, no significant changes were found in $\beta$-catenin expression following IP6 treatment at the mRNA and protein levels. By contrast, IP6 enabled the increased expression and membrane localization of E-cadherin in the treated cells, which would indicate elevated cell adhesion.

$\mathrm{N}$-cadherin belongs to the transmembrane adhesion proteins whose expression is required for collective cell migration. Increased $\mathrm{N}$-cadherin levels are correlated with epithelial to mesenchymal transition and tumor invasion (29). In the present study, the expression of $\mathrm{N}$-cadherin decreased at all time intervals upon treatment with 0.2 and $1 \mathrm{mM}$ IP6 concentrations. These changes were further associated with its subcellular localization (data not shown).

Transmembrane glycoprotein EpCAM is involved in cellular proliferation, migration and differentiation. It is also known to be highly expressed in epithelial carcinomas (30). ICAM-1 is expressed in endothelial cells (31). While normal colonic cells lack ICAM-1, tumor cells are known to exhibit increased expression of this molecule. A previous study determined that increased expression was present in colon cancer cells and that well-differentiated tumors exhibited the highest 
levels (32). IP6 treatment changed the expression of the two aforementioned markers, although these changes did not show a decisively linear trend, suggesting that these molecules are not a primary marker of IP6 in this model.

MMPs serve an important role in the local and systemic spread of malignant tumors. MMP-2 and MMP-9 degrade the extracellular matrix to enable invasion and metastasis of cells. IP6 has already demonstrated an inhibitory effect on MMP-9 secretion in breast cancer MDA-MB231 cells (16). Another study in Caco-2 cells demonstrated an increase in the expression of MMP-2 mRNA following treatment with $1 \mathrm{mM}$ IP6 for $1 \mathrm{~h}$, followed by a decrease in the expression at longer time intervals, while the expression of MMP-9 was neither constitutively expressed nor induced by IP6 (33). The results of the present study suggest a significant decrease in MMP-2 and MMP-9 mRNA levels in SW620 cells exposed to IP6 at all treatment intervals and used doses.

In conclusion, the present results demonstrate the ability of IP6 to alter the migration, adhesion and invasion in the SW620 cell line. Thus, IP6 is a promising anticancer agent that exerts its effects on multiple aspects of CRC progression. The reduction in $\mathrm{N}$-cadherin levels and increase in E-cadherin levels indicate that one of the IP6 targets could be the reversion of the epithelial-mesenchymal transition; however, levels of other EMT markers following IP6 treatment should be investigated in future studies.

\section{Acknowledgements}

Not applicable.

\section{Funding}

This study was supported by the grant PROGRESS Q40 01 of Charles University, Faculty of Medicine in Hradec Králové.

\section{Availability of data and materials}

The authors declare that the datasets used and/or analysed during the current study are available from the corresponding author on reasonable request

\section{Authors' contributions}

LS and VH designed the study and experiments; LS, AJ, ER, $\mathrm{KC}$ and $\mathrm{VH}$ performed the experiments; $\mathrm{LS}$ and $\mathrm{VH}$ conducted the statistical analysis; and LS, VK, VH, ER and KC wrote the manuscript.

\section{Ethics approval and consent to participate}

Not applicable.

\section{Patient consent for publication}

Not applicable.

\section{Competing interests}

The authors declare that they have no competing interests.

\section{References}

1. McGuire S: World Cancer Report 2014. Geneva, Switzerland: World Health Organization, International Agency for Research on Cancer, WHO Press, 2015. Adv Nutr 7: 418-419, 2016.

2. Arnold M, Sierra MS, Laversanne M, Soerjomataram I, Jemal A and Bray F: Global patterns and trends in colorectal cancer incidence and mortality. Gut 66: 683-691, 2017.

3. Liu G, Song Y, Cui L, Wen Z and Lu X: Inositol hexaphosphate suppresses growth and induces apoptosis in HT-29 colorectal cancer cells in culture: PI3K/Akt pathway as a potential target. Int J Clin Exp Pathol 8: 1402-1410, 2015.

4. Vucenik I, Ramakrishna G, Tantivejkul K, Anderson LM and Ramljak D: Inositol hexaphosphate (IP6) blocks proliferation of human breast cancer cells through a PKCdelta-dependent increase in $\mathrm{p} 27 \mathrm{Kip} 1$ and decrease in retinoblastoma protein (pRb) phosphorylation. Breast Cancer Res Treat 91: 35-45, 2005.

5. Vucenik I, Tantivejkul K, Zhang ZS, Cole KE, Saied I and Shamsuddin AM: IP6 in treatment of liver cancer. I. IP6 inhibits growth and reverses transformed phenotype in HepG2 human liver cancer cell line. Anticancer Res 18: 4083-4090, 1998.

6. Gu M, Roy S, Raina K, Agarwal C and Agarwal R: Inositol hexaphosphate suppresses growth and induces apoptosis in prostate carcinoma cells in culture and nude mouse xenograft: PI3K-Akt pathway as potential target. Cancer Res 69: 9465-9472, 2009.

7. Wawszczyk J, Kapral M, Lodowska J, Jesse K, Hollek A and Węglarz L: Antiproliferative effect of inositol hexaphosphate on human skin melanoma cells in vitro. Acta Pol Pharm 72: 895-900, 2015.

8. Wei J, Cheang T, Tang B, Xia H, Xing Z, Chen Z, Fang Y, Chen W, $\mathrm{Xu} \mathrm{A}$, Wang S, et al: The inhibition of human bladder cancer growth by calcium carbonate/CaIP6 nanocomposite particles delivering AIB1 siRNA. Biomaterials 34: 1246-1254, 2013.

9. El-Sherbiny YM, Cox MC, Ismail ZA, Shamsuddin AM and Vucenik I: G0/G1 arrest and S phase inhibition of human cancer cell lines by inositol hexaphosphate (IP6). Anticancer Res 21: 2393-2403, 2001.

10. Owen RW, Weisgerber UM, Spiegelhalder B and Bartsch H: Faecal phytic acid and its relation to other putative markers of risk for colorectal cancer. Gut 38: 591-597, 1996.

11. Bozsik A, Kökény S and Olah E: Molecular mechanisms for the antitumor activity of inositol hexakisphosphate (IP6). Cancer Genomics Proteomics 4: 43-51, 2007.

12. Cholewa K, Parfiniewicz B, Bednarek I, Swiatkowska L, Jezienicka E, Kierot J and Weglarz L: The influence of phytic acid on TNF-alpha and its receptors genes' expression in colon cancer Caco-2 cells. Acta Pol Pharm 65: 75-79, 2008.

13. Sakamoto K, Venkatraman G and Shamsuddin AM: Growth inhibition and differentiation of HT-29 cells in vitro by inositol hexaphosphate (phytic acid). Carcinogenesis 14: 1815-1819, 1993.

14. Fu M, Song Y, Wen Z, Lu X and Cui L: Inositol hexaphosphate and inositol inhibit colorectal cancer metastasis to the liver in BALB/c mice. Nutrients 8: 8, 2016.

15. Kapral M, Wawszczyk J, Jurzak M, Hollek A and Weglarz L: The effect of inositol hexaphosphate on the expression of selected metalloproteinases and their tissue inhibitors in IL-1 $\beta$-stimulated colon cancer cells. Int J Colorectal Dis 27: 1419-1428, 2012.

16. Tantivejkul K, Vucenik I and Shamsuddin AM: Inositol hexaphosphate (IP6) inhibits key events of cancer metastasis: I. In vitro studies of adhesion, migration and invasion of MDA-MB231 human breast cancer cells. Anticancer Res 23: 3671-3679, 2003

17. Tantivejkul K, Vucenik I and Shamsuddin AM: Inositol hexaphosphate (IP6) inhibits key events of cancer metastasis: II. Effects on integrins and focal adhesions. Anticancer Res 23: 3681-3689, 2003

18. Livak KJ and Schmittgen TD: Analysis of relative gene expression data using real-time quantitative PCR and the 2(-Delta Delta C(T)) method. Methods 25: 402-408, 2001.

19. Schroterova L, Haskova P, Rudolf E and Cervinka M: Effect of phytic acid and inositol on the proliferation and apoptosis of cells derived from colorectal carcinoma. Oncol Rep 23: 787-793, 2010.

20. Shamsuddin AM, Vucenik I and Cole KE: IP6: A novel anticancer agent. Life Sci 61: 343-354, 1997.

21. McFadden DW, Riggs DR, Jackson BJ and Cunningham C: Corn-derived carbohydrate inositol hexaphosphate inhibits Barrett's adenocarcinoma growth by pro-apoptotic mechanisms. Oncol Rep 19: 563-566, 2008. 
22. Sharma G, Singh RP and Agarwal R: Growth inhibitory and apoptotic effects of inositol hexaphosphate in transgenic adenocarcinoma of mouse prostate (TRAMP-C1) cells. Int J Oncol 23: 1413-1418, 2003.

23. Somasundar P, Riggs DR, Jackson BJ, Cunningham C, Vona-Davis L and McFadden DW: Inositol hexaphosphate (IP6): A novel treatment for pancreatic cancer. J Surg Res 126: 199-203, 2005.

24. Vucenik I, Kalebic T, Tantivejkul K and Shamsuddin AM: Novel anticancer function of inositol hexaphosphate: Inhibition of human rhabdomyosarcoma in vitro and in vivo. Anticancer Res 18: 1377-1384, 1998.

25. Vucenik I, Tomazic VJ, Fabian D and Shamsuddin AM: Antitumor activity of phytic acid (inositol hexaphosphate) in murine transplanted and metastatic fibrosarcoma, a pilot study. Cancer Lett 65: 9-13, 1992.

26. Oloumi A, McPhee T and Dedhar S: Regulation of E-cadherin expression and beta-catenin/Tcf transcriptional activity by the integrin-linked kinase. Biochim Biophys Acta 1691: 1-15, 2004.

27. Stockinger A, Eger A, Wolf J, Beug H and Foisner R: E-cadherin regulates cell growth by modulating proliferation-dependent beta-catenin transcriptional activity. J Cell Biol 154: 1185-1196, 2001.
28. Saad N, Esa NM and Ithnin H: Suppression of $\beta$-catenin and cyclooxygenase-2 expression and cell proliferation in azoxymethane-induced colonic cancer in rats by rice bran phytic acid (PA). Asian Pac J Cancer Prev 14: 3093-3099, 2013.

29. Todosi AM, Gavrilescu MM, Aniţei GM, Filip B and Scripcariu V: Colon cancer at the molecular level - usefulness of epithelial-mesenchymal transition analysis. Rev Med Chir Soc Med Nat Iasi 116: 1106-1111, 2012.

30. Dai M, Yuan F, Fu C, Shen G, Hu S and Shen G: Relationship between epithelial cell adhesion molecule (EpCAM) overexpression and gastric cancer patients: A systematic review and meta-analysis. PLoS One 12: e0175357, 2017.

31. Yang Y, Jun CD, Liu JH, Zhang R, Joachimiak A, Springer TA and Wang JH: Structural basis for dimerization of ICAM-1 on the cell surface. Mol Cell 14: 269-276, 2004.

32. Paschos KA, Canovas D and Bird NC: The role of cell adhesion molecules in the progression of colorectal cancer and the development of liver metastasis. Cell Signal 21: 665-674, 2009.

33. Kapral M, Wawszczyk J, Jurzak M, Dymitruk D and Weglarz L: Evaluation of the expression of metalloproteinases 2 and 9 and their tissue inhibitors in colon cancer cells treated with phytic acid. Acta Pol Pharm 67: 625-629, 2010. 